\title{
Wide applications of Chloroquine other than antimalarial
}

\author{
Ismail Ibrahim ${ }^{1}$, Barra Alani ${ }^{1}$, and Ameer Alwash ${ }^{2}$ \\ ${ }^{1}$ Al-Bayan University \\ ${ }^{2}$ Affiliation not available
}

August 23, 2020

\begin{abstract}
Chloroquine (CQ) was and still considered as the most common agent in treatment and prophylaxis of malaria, it also possesses many different pharmacological and biological activities that make it able to be used as a therapy or adjuvant therapy for many types of diseases. CQ exhibits anticancer activity alone or as adjuvants with other agents against many kinds of tumors. Its activities also were approved as anti-inflammatory agent in rheumatoid and other autoimmune diseases like systemic lupus and rheumatic arthritis. Its important role in improvement of many metabolic disorders like hypertension, hyperglycemia, and lipid profile disturbances was also established. CQ can act against different microbial infections such as many types of virus, bacteria and fungus by different mechanisms of action. Furthermore, its dermatological role in treatment of many skin diseases was demonstrated. Recently, CQ showed very responsive role in curing and prevention of covoid-19 virus. This review summarizes intensively the multiple therapeutic applications of $\mathrm{CQ}$ and discusses the possible mechanisms of action for these applications.
\end{abstract}

\section{Hosted file}

chloroquine final review.docx available at https://authorea.com/users/352903/articles/477157wide-applications-of-chloroquine-other-than-antimalarial

\section{Hosted file}

chloroquine final review without authors.docx available at https://authorea.com/users/352903/ articles/477157-wide-applications-of-chloroquine-other-than-antimalarial 